\title{
Underinsurance in Primary Care: A Report from the State Networks of Colorado Ambulatory Practices and Partners (SNOCAP)
}

\author{
Kenton Voorhees, MD, Douglas H. Fernald, MA, Caroline Emsermann, MS, \\ Linda Zittleman, MSPH, Peter C. Smith, MD, Bennett Parnes, MD, \\ Kathy Winkelman, BS, and John M. Westfall, MD, MPH
}

Background: There has been considerable focus on the uninsured from national and state levels. There are also many Americans who have health insurance but are unable to afford their recommended care and are considered underinsured. This purpose of this study was to determine the prevalence of underinsurance among patients seen in primary care clinics.

Methods: Patients in 37 primary care practices in 3 practice-based research networks completed a survey to elicit the prevalence of underinsurance among those who had insurance for a full 12 months, including private insurance, Medicare, and Medicaid. Being underinsured was based on patients reporting the delay or omission of recommended care because of their inability to afford it.

Results: Of those with insurance for a full year, $36.3 \%$ were underinsured. Of those who were underinsured, $50.2 \%$ felt that their health suffered because they could not afford recommended care, a rate similar among those who were uninsured.

Conclusions: When evaluating underinsurance in primary care offices, using an experiential definition based on self-reports of patients about their inability to pay for recommended health care despite having insurance, the prevalence is quite high. It is important for the primary care physician to understand that a substantial percentage of their patients may not follow through with their recommendations because of cost, despite having insurance. This also has significant implications when considering health care reform, particularly considering that these patients reported that their health suffered at a rate equal to that of the uninsured. (J Am Board Fam Med 2008;21:309-316.)

The cost of health care and problems with access to care dominate both state and national health care reform discussions. The 47 million Americans without health insurance ${ }^{1}$ are, rightly, a major focus of this discussion. Meanwhile, many Americans with insurance also face prohibitive costs and prob-

This article was externally peer reviewed.

Submitted 2 January 2008; revised 3 March 2008; accepted 27 March 2008.

From the Department of Family Medicine, University of Colorado, Denver, School of Medicine (KV, DHF, CE, LZ, PCS, BP, JMW); the Colorado Research Network (DHF, BP); the High Plains Research Network (LZ, JMW, KW); and the Building Investigative Practices for Better Health Outcomes Research Network (PCS).

Funding: The Colorado Health Foundation.

Conflict of interest: Dr. Voorhees is employed as the Director of Graduate Medical Education for The Colorado Health Foundation. There are no known conflicts of interest among the other authors.

Corresponding author: Kenton Voorhees, MD, Department of Family Medicine, University of Colorado Denver School of Medicine, AO1, L15, Mail Stop F496, PO Box 6511, Aurora, CO 80045-6508 (E-mail: kent.voorhees@ uchsc.edu). lems with access to care. As many as $16 \%$ of the nonelderly adult US population with private insurance have substantial problems paying their medical bills. ${ }^{2}$ Many of them skip recommended tests, delay seeking care, or do not fill their prescriptions because of cost. ${ }^{2}$ Patients who are unable to afford recommended health care despite having insurance are considered to be underinsured. Definitions of underinsurance vary, with many definitions based on financial criteria. Those who spend more than $10 \%$ of their income on health care, or $5 \%$ for those below $200 \%$ of the federal poverty level, are considered to be underinsured. ${ }^{3-6}$ Other studies have defined underinsurance based on patient's self-reported experience about being unable to afford recommended health care despite having insurance; it may not necessarily be related to their income. ${ }^{7,8}$ This study follows this experiential definition. All definitions agree that underinsurance results in an insured patient not obtaining recommended care because they cannot afford it. Recent 
studies using income-based definitions of underinsurance and general population surveys have found that underinsured patients have outcomes as equally poor as uninsured patients. ${ }^{6,7}$ The purpose of this study was to determine the prevalence of underinsurance in primary care practices. Previous studies have not evaluated this. Understanding the prevalence of underinsurance may be useful for primary care providers when managing their patients. An understanding among primary care providers that a substantial percentage of patients may not be able to follow their recommendations because of cost may influence the care that they provide. Additional conversations with patients may be necessary to understand this issue.

This study also included Medicare and Medicaid patients, who have typically been excluded from other studies. Although not designed to extrapolate the number of underinsured patients participating this study to the population of the state or the country as a whole, this study is intended to point out that the problem of underinsurance may be significant and should be considered when exploring options for health care reform. That this study only looked at patients who were willing to come to the office to see a health care provider and excluded those who may not have even been willing to do that out of concerns about the costs suggests that this study underestimates the total percentage of underinsured.

\section{Methods}

\section{Setting}

This study was conducted in 3 practice-based research networks within the State Networks of Colorado Ambulatory Practices and Partners (SNOCAP). The Colorado Research Network (CaReNet) consists of 35 practices that generally care for underserved populations, including community health centers, residencies, and hospitalaffiliated practices. The High Plains Research Network (HPRN) is an integrated network of 25 practices, 11 hospitals, nursing homes, and communities in rural eastern Colorado. Building Investigative practices for better Health Outcomes Research Network (BIGHORN) consists of 15 private practices in urban, suburban, and rural Colorado. This study was conducted only in primary care practices.
Table 1. Definitions of Insurance Strata

\begin{tabular}{|c|c|}
\hline Stratum & Definition \\
\hline Uninsured & $\begin{array}{l}\text { Patient marked "no insurance" during } \\
\text { the past } 12 \text { months }\end{array}$ \\
\hline Partially insured & $\begin{array}{l}\text { Patient marked "no insurance" and at } \\
\text { least one other type of insurance } \\
\text { during the past } 12 \text { months }\end{array}$ \\
\hline Adequately insured & $\begin{array}{l}\text { Patient marked at least one type of } \\
\text { insurance during the past } 12 \text { months } \\
\text { and marked "no" or "don't know" for } \\
\text { all indicators of underinsurance }\end{array}$ \\
\hline Underinsured & $\begin{array}{l}\text { Patient marked at least one type of } \\
\text { insurance during the past } 12 \text { months } \\
\text { and marked "yes" for at least one } \\
\text { indicator of underinsurance }\end{array}$ \\
\hline
\end{tabular}

\section{Survey Design}

We designed a self-administered, anonymous, voluntary survey that asked patients to answer questions about their health insurance over the past 12 months, who pays for their health insurance, if they delayed or were unable to get care because of difficulty paying for it, and whether their health had suffered because of their inability to afford recommended care. The survey also included questions about out-of-pocket medical expenses paid in the past 12 months, health status, demographics, and annual household income. The survey was available in Spanish or English. The survey was reviewed by the High Plains Research Network Community Advisory Council and piloted with a small sample of patients in 2 primary care clinics.

All practices in SNOCAP were eligible to participate and were invited to select a single day to conduct the study. On the selected study day, consecutive patients seen in the clinic were asked by the front office staff to complete the anonymous survey before leaving. A parent, family member, or representative accompanying the patient could complete the survey if the patient was a minor or if the patient was unable to complete the survey themselves. Completed surveys were returned to a collection box at the clinic. Complete and undistributed surveys were returned to the study team for analysis. Practices recorded the number of patients seen on the study day.

\section{Descriptive Statistics}

Patients were categorized into 4 insurance strata based on their self-reported insurance status (Table 1). Frequency distributions describe the patient population, which included patient demographics; insur- 


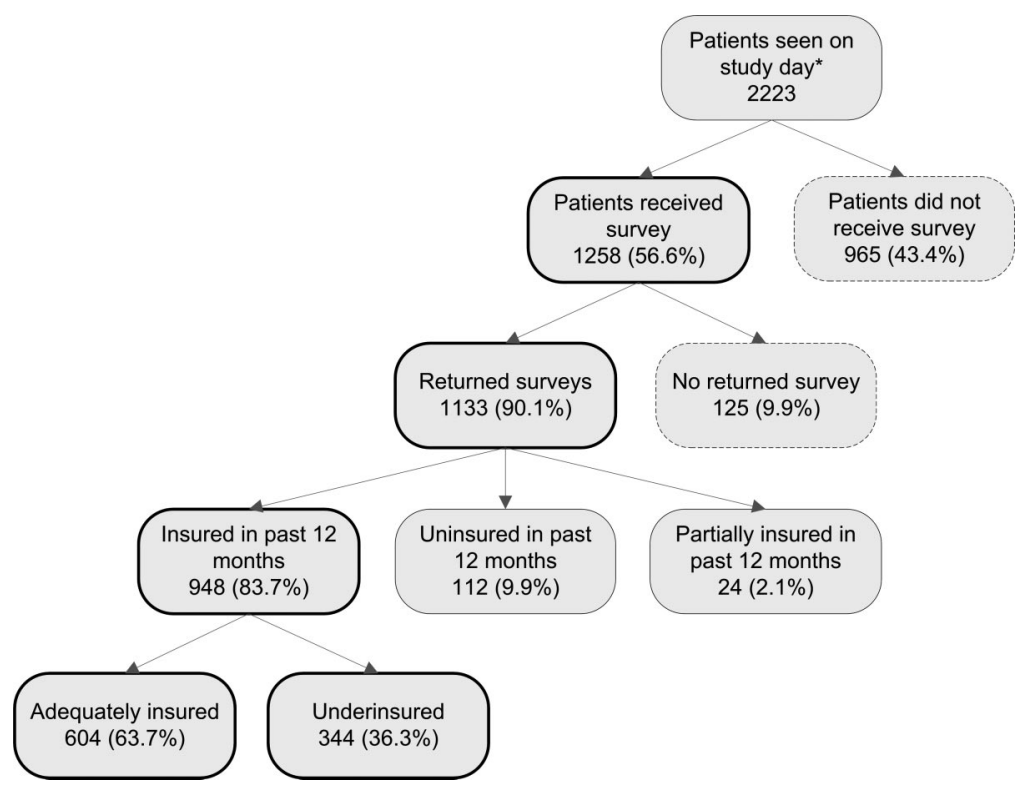

Figure 1. Survey response diagram and underinsured sample. *Total number of patients seen on the study day was recorded by each practice except one small practice which provided an average daily patient count (40 patients per day).

ance type (Medicare only, Medicaid only, private only, combination of private insurance); and indicators of underinsurance, including delay in seeking care, inability to see a regular doctor, inability to see a specialist, inability to fill a prescription, inability to have a test, and inability to receive any other medical care because of cost (see Appendix).

Comparisons of the frequencies of patient demographic characteristics between patients classified as underinsured and adequately insured are also included. The prevalence of underinsurance was estimated by the percentage of patients classified as underinsured out of the total insured patients.

\section{Mixed-Effects Logistic Regression Analysis}

Mixed-effects logistic regression models, adjusting for the clustering of patients within practices, were performed to identify demographic associations among patients classified as underinsured versus adequately insured. Covariates included patient demographics; insurer type (self-paid, employer paid); insurance type (Medicaid, Medicare); and if the patients felt their health suffered because they were unable to afford the cost of any needed care (yes, no/don't know). Thus, multiple univariate models were performed that adjusted for each covariate separately as a fixed effect. Similar analyses were performed for patients classified as underinsured versus uninsured. Responses to questions regarding delay in care because of a lack of funds were run as outcome variables against the type of insurance (Medicare only, Medicaid only, private only, combination of private insurance) among underinsured patients in similar models. Because the interclass correlation of patients within practices was .038 $(P=.04)$, analyses were adjusted for practice as a random effect. All analyses were performed using SAS software (version 9.1; SAS Institute, Inc., Cary, NC). Mixed-effects logistic regression analyses were performed using the Proc Glimmix macro on complete data. Because of multiple tests, statistical associations are determined at the $\alpha=$ .01 .

This study was approved by the 5 hospital system institutional review boards that had clinics participating in the study. Overall human subjects approval was granted by the Colorado Multiple Institutional Review Board.

\section{Results}

A total of 1133 surveys were returned from 1258 distributed to patients (Figure 1). Eleven percent of the surveys were completed in Spanish and the rest were completed in English. Practice characteristics of the 37 participating practices are displayed in Table 2. 
Table 2. Types of Clinics that Participated in this Study $(\mathrm{n}=37)$

\begin{tabular}{lc}
\hline Characteristic & $\mathrm{N}(\%)^{*}$ \\
\hline Family medicine & $30(81.1)$ \\
Internal medicine & $4(10.8)$ \\
Pediatrics & $2(5.4)$ \\
Geriatrics & $1(2.7)$ \\
Urban/suburban & $21(56.8)$ \\
Rural & $16(43.2)$ \\
Community health center & $11(29.7)$ \\
Private practice & $11(29.7)$ \\
Hospital affiliate & $10(27.0)$ \\
Residency practice & $5(13.5)$ \\
\hline
\end{tabular}

*Totals may not equal $100 \%$ because of rounding.

Family medicine practices were more heavily represented; whereas rural and urban practices as well as community health centers, private practices, and hospital affiliates were more evenly represented.

Patient characteristics are displayed in Table 3. Patients tended to be between the ages of 18 and 64 (71.8\%; mean age, 44.4 years; SD, 20.15 years); female; non-Hispanic white; and privately insured during the year with a self-reported annual income of $<\$ 25,000$. Patients also tended to report they were in good to excellent health. The indicators for underinsurance reported by the 344 underinsured patients were delayed seeking care $(232,67.4 \%)$; unable to fill a prescription $(211,61.3 \%)$; unable to see regular doctor $(176,51.2 \%)$; unable to see a specialist $(160,46.5 \%)$, unable to receive some other recommended medical care $(139,40.4 \%)$; or unable to have a test $(125,36.3 \%)$ because of the inability to afford the care. We found no associations between any indicators for underinsurance and insurance type $(P>.05)$.

Overall, $30.4 \%$ of our sample was classified as underinsured. Of the 948 patients with insurance for a full year, including Medicare or Medicaid, $36.3 \%$ were classified as underinsured (Figure 1). Of those who were underinsured, $19.2 \%$ had Medicare and $32.6 \%$ had Medicaid.

Characteristics of underinsured and insured patients are presented in Table 4. Higher proportions of women, Hispanics, lower incomes, and patients aged 18 to 39 were underinsured than adequately insured. Underinsured patients also reported higher proportions of fair or poor health status and that their health had suffered. Presented in Table 5 are odds ratios of being underinsured versus adequately insured by pa-
Table 3. Demographic and Other Characteristics of Survey Respondents $(\mathrm{n}=\mathbf{1 1 3 3})$

\begin{tabular}{lc}
\hline Characteristic & $\mathrm{N}(\%)$ \\
\hline Age (years) & \\
$\leq 17$ & $113(10.0)$ \\
$8-39$ & $424(37.4)$ \\
$40-64$ & $390(34.4)$ \\
$\geq 65$ & $206(18.2)$ \\
Sex & \\
Male & $285(25.2)$ \\
Female & $615(54.3)$ \\
Unknown & $233(20.6)$ \\
Race/ethnicity & \\
White (non-Hispanic) & $672(59.3)$ \\
African-American (non-Hispanic) & $60(5.3)$ \\
Other (non-Hispanic) & $48(4.2)$ \\
Hispanic & $317(28.0)$ \\
Unknown & $36(3.2)$ \\
Income & \\
$<\$ 25,000$ & $522(46.1)$ \\
\$25,000-\$49,999 & $220(19.4)$ \\
$\geq \$ 50,000$ & $239(21.1)$ \\
Unknown & $152(13.4)$ \\
General health status & \\
Good, very good, or excellent & \\
Fair or poor & $734(64.8)$ \\
Unknown & $342(30.2)$ \\
Medicare only & \\
Medicaid only & \\
Private only & \\
All others & \\
No insurance & \\
Missing & $(17.0)$ \\
\hline & \\
&
\end{tabular}

tient characteristics. Patients who reported their general health as fair to poor and who believe their health suffered because they were unable to afford the cost of necessary care also had higher odds of being underinsured $(P<.01)$. When similar adjusted univariate analyses were performed comparing the underinsured with the uninsured patient population, no statistical differences among the demographic characteristics were found $(P>.05)$ with the exception of income (data not shown). Patients reporting an annual income of $<\$ 20,000$ had higher odds of being uninsured than underinsured (odds ratio, 0.28; 95\% CI, 0.11-0.72). Patients who were female, younger than 65, African-American or Hispanic, or who had an annual self-reported income of $<\$ 50,000$ had higher odds of being underinsured than adequately insured $(P<.01)$. In addition, patients who reported Medi- 
Table 4. Demographic Characteristics of Underinsured Patients Compared with Those of Adequately Insured Patients*

\begin{tabular}{|c|c|c|c|}
\hline \multirow[b]{2}{*}{ Characteristic } & \multicolumn{2}{|c|}{ Insured } & \multirow[b]{2}{*}{$\begin{array}{l}\text { Uninsured } \\
(\mathrm{n}=112)\end{array}$} \\
\hline & $\begin{array}{l}\text { Underinsured } \\
(\mathrm{n}=344)\end{array}$ & $\begin{array}{l}\text { Adequately insured } \\
\qquad(\mathrm{n}=604)\end{array}$ & \\
\hline \multicolumn{4}{|l|}{$\operatorname{Age}^{\dagger}$} \\
\hline$\leq 17$ & $22(6.4)$ & $57(9.4)$ & $7(6.3)$ \\
\hline $18-39$ & $166(48.3)$ & $176(29.1)$ & $57(50.9)$ \\
\hline $40-64$ & $130(37.8)$ & $197(32.6)$ & $45(40.2)$ \\
\hline$\geq 65$ & $26(7.6)$ & $174(28.8)$ & $3(2.7)$ \\
\hline Insured Patients & $344(36.3)$ & $604(63.7)$ & \\
\hline \multicolumn{4}{|l|}{$\operatorname{Sex}^{\dagger}$} \\
\hline Male & $66(19.2)$ & $158(26.2)$ & $63(56.3)$ \\
\hline Female & $228(66.3)$ & $296(49.0)$ & $25(22.3)$ \\
\hline Unknown & $50(14.5)$ & $150(24.8)$ & $24(21.4)$ \\
\hline \multicolumn{4}{|l|}{ Race/ethnicity $^{\dagger}$} \\
\hline White (non-Hispanic) & $189(54.9)$ & $411(68.1)$ & $46(41.1)$ \\
\hline African-American (non-Hispanic) & $27(7.9)$ & $22(3.6)$ & $7(6.3)$ \\
\hline Other (non-Hispanic) & $12(3.5)$ & $31(5.1)$ & $4(3.6)$ \\
\hline Hispanic & $112(32.6)$ & $134(22.2)$ & $55(49.1)$ \\
\hline Unknown & $4(1.2)$ & $6(1.0)$ & $0(0)$ \\
\hline \multicolumn{4}{|l|}{ Income $^{\dagger}$} \\
\hline$<\$ 25,000$ & $184(53.5)$ & $230(38.1)$ & $79(70.5)$ \\
\hline$\$ 25,000-\$ 49,999$ & $87(25.3)$ & $111(18.4)$ & $12(10.7)$ \\
\hline$\geq \$ 50,000$ & $51(14.8)$ & $179(29.6)$ & $5(4.5)$ \\
\hline Unknown & $22(6.4)$ & $84(13.9)$ & $16(14.3)$ \\
\hline \multicolumn{4}{|c|}{ Health suffered from inability to get care because of cost ${ }^{\dagger}$} \\
\hline Yes & $173(50.3)$ & $8(1.3)$ & $52(46.4)$ \\
\hline No/don't know & $156(45.3)$ & $577(95.5)$ & $52(46.4)$ \\
\hline Unknown & $15(4.4)$ & $19(3.2)$ & $8(7.1)$ \\
\hline \multicolumn{4}{|l|}{ General health status $^{\dagger}$} \\
\hline Good, very good, or excellent & $202(58.7)$ & $445(73.7)$ & $54(48.2)$ \\
\hline Fair or poor & $134(39.0)$ & $136(22.5)$ & $53(47.3)$ \\
\hline Unknown & $8(2.3)$ & $23(3.8)$ & $5(4.5)$ \\
\hline \multicolumn{4}{|l|}{ Insurance Type } \\
\hline Medicare only & $28(8.1)$ & $58(9.6)$ & \\
\hline Medicaid only & $83(24.1)$ & $110(18.2)$ & \\
\hline Private only & $73(21.2)$ & $140(23.2)$ & \\
\hline All others & $160(46.5)$ & $296(49.0)$ & \\
\hline
\end{tabular}

All values shown as $\mathrm{n}(\%)$.

${ }^{*}$ Does not include the partially insured (those who had insurance but not for the entire year, which was an additional 73 patients). ${ }^{\dagger} P<.01$ for unadjusted $\chi^{2}$ test. Analysis for this table did not adjust for practice as a random effect.

care as at least one form of insurance had a lower odds of being underinsured $(P<.001)$ than adequately insured; whereas no statistical associations were found among insured patients and those reporting Medicaid as at least one form of insurance $(P=.219)$.

\section{Discussion}

This study of patients in Colorado who were seen in primary care practices found that more than one third $(36.3 \%)$ with insurance were underinsured and that they were very likely to report that their health had suffered because of the inability to afford care. Our finding of the percentage of underinsured is much higher than estimates of $7 \%$ to $12 \%$ found in national samples of nonelderly adults, ${ }^{6,7}$ and higher than the $4.5 \%$ estimate for Colorado in $1995 .^{3}$ The definition used in this study was based on experiential criteria as opposed 
Table 5. Underinsured Versus Adequately Insured: Odds Ratios of Being Underinsured by Patient Demographic and Insurance Characteristics

\begin{tabular}{|c|c|c|}
\hline \multirow[b]{2}{*}{ Demographic Variable } & \multicolumn{2}{|c|}{$\begin{array}{c}\text { Underinsured Versus Adequately Insured (n } \\
\qquad=948)\end{array}$} \\
\hline & Odds Ratio (95\% CI) & $P$ \\
\hline \multicolumn{3}{|l|}{ Sex } \\
\hline Female & $2.25(1.56-3.24)$ & \multirow{3}{*}{$<.001$} \\
\hline Unknown & $1.28(0.80-2.05)$ & \\
\hline Male & $1.00(1.00-1.00)$ & \\
\hline \multicolumn{3}{|l|}{ Age } \\
\hline$\leq 17$ & $2.51(1.31-4.81)$ & \multirow{4}{*}{$<.001$} \\
\hline $18-39$ & $6.18(3.86-9.92)$ & \\
\hline $40-64$ & $4.39(2.74-7.04)$ & \\
\hline$\geq 65$ & $1.00(1.00-1.00)$ & \\
\hline \multicolumn{3}{|l|}{ Race/ethnicity* } \\
\hline African-American (non-Hispanic) & $2.63(1.44-4.83)$ & \multirow{4}{*}{.001} \\
\hline Hispanic & $1.76(1.26-2.45)$ & \\
\hline Other (non-Hispanic) & $0.84(0.42-1.69)$ & \\
\hline White (non-Hispanic) & $1.00(1.00-1.00)$ & \\
\hline \multicolumn{3}{|l|}{ Rural } \\
\hline Yes & $0.85(0.56-1.29)$ & \multirow[t]{2}{*}{.462} \\
\hline No & $1.00(1.00-1.00)$ & \\
\hline \multicolumn{3}{|l|}{ Annual income } \\
\hline$<\$ 25,000$ & $2.70(1.85-3.94)$ & \multirow{4}{*}{$<.001$} \\
\hline$\$ 25,000-\$ 49,999$ & $2.69(1.76-4.10)$ & \\
\hline Missing & $0.92(0.52-1.62)$ & \\
\hline$\geq \$ 50,000$ & $1.00(1.00-1.00)$ & \\
\hline \multicolumn{3}{|l|}{ General health status } \\
\hline Poor/fair & $2.15(1.59-2.89)$ & \multirow{3}{*}{$<.001$} \\
\hline Missing & $0.85(0.37-1.94)$ & \\
\hline Good/excellent & $1.00(1.00-1.00)$ & \\
\hline \multicolumn{3}{|c|}{ I pay or a family member pays for my insurance } \\
\hline Yes & $1.01(0.76-1.34)$ & \multirow[t]{2}{*}{.967} \\
\hline No & $1.00(1.00-1.00)$ & \\
\hline \multicolumn{3}{|c|}{ My employer or a family member's employer pays for my insurance } \\
\hline Yes & $0.65(0.46-0.90)$ & \multirow[t]{2}{*}{.010} \\
\hline No & $1.00(1.00-1.00)$ & \\
\hline \multicolumn{3}{|l|}{ Government pays for my insurance } \\
\hline Yes & $0.95(0.72-1.26)$ & \multirow[t]{2}{*}{.722} \\
\hline No & $1.00(1.00-1.00)$ & \\
\hline \multicolumn{3}{|c|}{ Health suffered from inability to get care because of cost* } \\
\hline Yes & $79.21(38.34-163.64)$ & \multirow[t]{2}{*}{$<.001$} \\
\hline No/don't know & $1.00(1.00-1.00)$ & \\
\hline \multicolumn{3}{|l|}{ Medicaid } \\
\hline Yes & $1.21(0.89-1.64)$ & \multirow[t]{2}{*}{.219} \\
\hline No & $1.00(1.00-1.00)$ & \\
\hline \multicolumn{3}{|l|}{ Medicare } \\
\hline Yes & $0.47(0.34-0.64)$ & $<.001$ \\
\hline No & $1.00(1.00-1.00)$ & \\
\hline
\end{tabular}

*Bolded values indicate statistical association at $\alpha=0.01$.

Note: Estimated odds ratio and $95 \% \mathrm{CI}$ are large when underinsured versus insured respondents are compared. This is because of the small number of insured respondents $(n=8)$ who reported that their health suffered because of high costs. 
to financial criteria used in many other studies. As costs shifting to patients increase over time the number of underinsured patients is expected to increase. As other studies have shown, we found that underinsured patients are more likely to report fair or poor health status than adequately insured patients; women and poorer patients are more often underinsured. Contrary to what has been reported elsewhere, we found that rural patients were not significantly more likely to report being underinsured. $^{6}$

Unlike previous studies on underinsurance, ${ }^{6,7}$ our study also included patients over the age of 64 and under the age of 18 , and those patients with Medicare, Medicaid, or both. Although those with Medicare seem less likely to be underinsured, this group still faces financial concerns when obtaining recommended care. Importantly, those with Medicaid seem to be equally likely to report being underinsured and in poorer general health as those with no insurance. Because this is a poorer patient population, contributions to their own care, even if in smaller amounts, may still cause them to forgo care because they did not feel that they could afford it. This has enormous implications for the current efforts at health care reform that may rely heavily on expanding Medicaid without other substantial reforms.

This study suggests that the underinsured outnumber the uninsured and that underinsurance does not defer the suffering associated with the inability to pay for care. Accordingly, merely increasing access to insurance does not seem to be the much-hoped-for panacea for solving the nation's health care crisis. Consideration of the extent of underinsurance is essential in any reform effort, especially if half of underinsured patients report that their health has suffered as a result, a rate equal to that of the uninsured. Our findings are consistent with those of the Kaiser Commission, which found that as many as 18 million nonelderly adults with private insurance coverage have significant problems paying their medical bills. ${ }^{2}$ The Kaiser Commission study also found that those with private insurance but medical debt were more likely to skip recommended tests, fail to fill a prescription, or postpone care because of cost.

This study has several limitations. Because of missing data, responses to the survey questions about out-of-pocket expense were difficult to interpret, which limited our ability make judgments about underinsurance based on income and medical expenses. This study was conducted in primary care offices in which patients self-reported their experiences so it is not known which delays or missed tests or examinations were of clinical significance. In addition, this sample may not be generalizable to the general population, although it does reflect reported demographics of those who seek medical care in primary care offices. A little over half of the patients seen in participating practices were offered a survey from the front office staff, which may have led to biased results. However, among those patients who received a survey, $90 \%$ returned it completed. Because this study was done on a single day in each practice, this sample of patients could be different from the practice as a whole, creating potential bias. Finally, this study likely underestimates the total number of underinsured people because some may be avoiding seeking care because of their underinsurance or because they have not yet exceeded their ability to pay for their care., ${ }^{2,7}$

\section{Conclusions}

To determine the prevalence of patients with insurance who were underinsured, this study used the practical approach of asking patients about their decisions to delay or forgo recommended care. Using this approach, $36.3 \%$ of the patients with insurance who were surveyed in primary care practices were underinsured. It is important for the primary care provider to understand that a substantial percentage of their patients may not follow through with their recommendations because of inability to afford the recommended care, despite having insurance. This may even include patients with Medicare and Medicaid. Understanding this issue may lead to additional conversations between primary care providers and their patients, which could potentially result in a modification of physician recommendations. Although this study was not designed to extrapolate the number of underinsured patients participating in this study to the population of the state or the country as a whole, it is intended to point out that the problem of underinsurance may be significant and should be considered when exploring options for health care reform. The fact that the study only looked at patients who were willing to come to the office to see a health care provider and excluded those who may not have even been willing to do that out of concerns of the costs would suggest that this study 
would underestimate the total percentage of underinsured. The burden of this could be significant given our finding that about $50 \%$ of underinsured patients felt that their health suffered because of inability to afford recommended care the same level as the uninsured patients.

This study highlights underinsurance as a significant problem that requires further research to define state and national prevalence, health outcomes, and potential solutions. This is particularly important when evidence suggests that those who are underinsured have outcomes equally poor as those who are uninsured. When considering health care reform it is essential to address underinsurance if the reform is an attempt to provide adequate financial protection from health care expenditures.

Thank you to The Colorado Health Foundation for funding this study. We thank all the participating SNOCAP practices for their dedicated efforts: Brush Family Medicine; Child Health Clinic; Colorado Springs Osteopathic Foundation and Family Medicine Center; Comprehensive Family Care Center; Durand Kahler, DO; Eastside Pediatric Clinic; Family Care Center; Family Care Southwest, PC; Family Medical Associates; Fort Morgan Internal Medicine; Generations Health Care; Haxtun Family Medicine Center; Internal Medicine-AOP; La Mariposa Family Health Center; Metro Community Provider NetworkParker Place; Nova Women's Care; Parke Health and Wellness Center (Burlington and Stratton); Plains Medical Centers (Limon and Strasburg); Richard Lamb, MD; Rose Family Medicine Center; Salud Family Health Centers (Brighton, Commerce City, Ft. Lupton, Ft. Morgan, and Sterling); Seniors Clinic; Southern Colorado Family Practice; Spanish Peaks Family Practice; St. Anthony's Family Medicine Center North; St. Anthony's Family Medicine Center West; Swedish Family Medicine Center; University Family Medicine Westminster; University Medicine Group Practice; Valley Medical Clinic; and Westside Health Center-Adult Clinic.

\section{References}

1. DeNavas-Walt C, Proctor BD, Smith J. Income, poverty, and health insurance coverage in the United States: 2006. US Census Bureau Current Population Reports, P60-233. Washington, DC: US Government Printing Office; 2007.

2. Hoffman C, Rowland D, Hamel EC. Medical debt and access to health care. Washington, DC: Kaiser Commission on Medicaid and the Uninsured; 2005.

3. Bashshur R, Smith DG, Stiles RA. Defining underinsurance: a conceptual framework for policy and empirical analysis. Med Care Rev 1993;50:199-218.

4. Kogan MD, Newacheck PW, Honberg L, Strickland B. Association between underinsurance and access to care among children with special health care needs in the United States. Pediatrics 2005;116:1162-9.

5. Schoen C, Doty MM, Collins SR, Holmgren AL. Insured but not protected: how many adults are underinsured? Health Aff (Millwood) 2005; Suppl Web Exclusives:W5-289-W5-302.

6. Ziller EC, Coburn AF, Yousefian AE. Out-of-pocket health spending and the rural underinsured. Health Aff (Millwood) 2006;25:1688-99.

7. State-specific prevalence estimates of uninsured and underinsured persons Behavioral Risk Factor Surveillance System, 1995. MMWR Morb Mortal Wkly Rep 1998;47:51-5.

8. Blendon RJ, Donelan K, Hill CA, Carter W, Beatrice D, Altman D. Paying medical bills in the United States. Why health insurance isn't enough. JAMA 1994;271:949-51.

\section{Appendix: Survey Items that Determined Underinsurance Status of Insured Patients*}

\section{During the past 12 months:}

Did you delay seeking medical care because of trouble paying for it?

Were you unable to see a specialist that you were referred to because of trouble paying for it?

Were you unable to make an appointment with a regular doctor because of trouble paying for it?

Were you unable to fill a recommended prescription because of trouble paying for it?

Were you unable to receive a recommended colonoscopy to screen for colorectal cancer because of trouble paying for it?

Were you unable to have any other test done that was recommended because of trouble paying for it?

Were you unable to receive any other medical care because of trouble paying for it?

*Response options were Yes, No, or Don't Know. A response of Yes to one or more of these indicated underinsurance. 